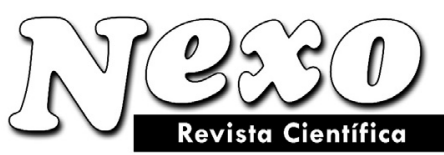

\title{
Diseño y montaje de una planta piloto para la extracción de Quitina y proteínas
}

\author{
D. Escorcia, D. Hernández, M. Sánchez y M. Benavente* \\ Facultad de Ingeniería Química, Universidad Nacional de Ingeniería (UNI) \\ PO Box 5595, Managua, Nicaragua \\ E-mail: bena@kth.se
}

(Recibido/received: 11-Septiembre-2009; aceptado/accepted: 22-Diciembre-2009)

\section{RESUMEN}

El proyecto se basó en el diseño y montaje de una planta piloto para la extracción química de Quitina y proteínas a partir de desechos de crustáceos (camarón y langostino). Se determinó el contenido de humedad del material y las condiciones experimentales óptimas de volumen y concentración de los reactivos involucrados en el proceso. Además, se realizó un análisis técnico y económico del mismo. Los resultados mostraron que la materia prima tiene un alto contenido de humedad entre $68-80 \%$ y que las condiciones experimentales para la obtención de Quitina dependen fuertemente de las características del material. Bajo estas condiciones se obtuvo una recuperación mayor del $98 \%$ para el caso de caparazón de camarón y de aproximadamente un 58\% en el caso del langostino. Por otro lado, para la extracción de proteínas se encontró que la mayor producción ocurre a $\mathrm{pH} 4.0$ y con soluciones provenientes del proceso de desproteinización, sin trituración previa de la materia prima. El estudio técnico proporcionó información básica sobre los costos e inversión del proceso operativo, datos sobre las instalaciones y los equipos asociados al proceso productivo. El análisis económico mostró que se debe tener una inversión inicial de US \$10,520.94 para el montaje de la planta piloto y de US $\$ 4,852.58$ para gastos de transporte y operación por seis meses.

Palabras claves: caparazón de camarón; langostino; método químico; planta piloto; proteínas, quitina.

\begin{abstract}
The aim of this project was the design and set up of a pilot plant for chitin and proteins chemical recovery from shrimp shells and squat lobsters. The moisture content of the material and optimal experimental conditions of volume and concentration of the process reagents were determined. Additionally, a technical and economical analysis of production process was performed. The results showed that the raw material has high moisture content, between $68-80 \%$ wet basis, and the experimental conditions for chitin extraction depend strongly on the material characteristics. Under these conditions, recuperation of $98 \%$ for shrimp shells and approximately of $58 \%$ for squad lobster was obtained. On the other hand, the proteins recovery showed that the largest production occurs at $\mathrm{pH} 4.0$ and using solutions from deproteination step without grinding of raw material. The technical study provided basic information about set up costs and operating process investment, and data about facilities and equipments related to productive process. The assessment revealed that an initial investment of US $\$ 10,520.94$ for pilot plant set up and US $\$ 4,852.58$ for transport and operating costs for six months must be done.
\end{abstract}

Keywords: chemical method; chitin; pilot plant; proteins; shrimp shell; squat lobster.

${ }^{*}$ Autor para la correspondencia 


\section{Benavente et al}

\section{INTRODUCCIÓN}

Actualmente, la producción de camarones y langostinos en Nicaragua se ha incrementado notablemente hasta ocupar el segundo lugar entre los principales rubros de exportación del país. Sin embargo, se estima que esta industria genera mensualmente aproximadamente 300 toneladas de desechos sólidos (caparazón de crustáceos entre otros). Estos desechos cuando son depositados sin ningún tratamiento previo, se deterioran rápidamente debido a la acción de los microorganismos provocando un efecto negativo en el medio ambiente y en la salud de los pobladores.

De acuerdo a Gerente et al. (2007) el caparazón de los crustáceos contiene una significativa cantidad de sales de calcio, el polímero Quitina $(15-25 \% \mathrm{w} / \mathrm{w})$ y proteínas, por lo que estos desechos constituyen, por sí mismos, una fuente de productos valiosos de interés comercial y de investigación, los cuales pueden ser aprovechados para diversos usos y aplicaciones. Uno de los principales usos de la Quitina es su utilización como materia prima para la obtención de Quitosano (ver figura 1) y Glucosamina. El Quitosano es un polisacárido nitrogenado que presenta las características de ser biodegradable, biológicamente renovable, biocompatible, no-tóxico y biofuncional (Malafaya et al., 2007).

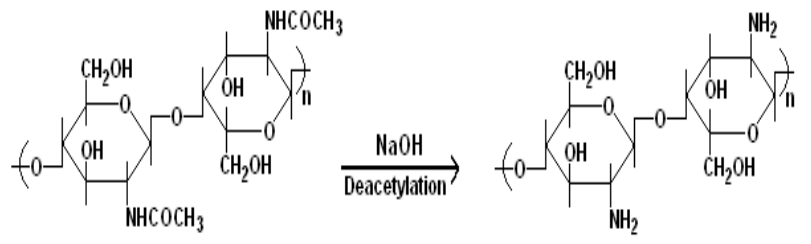

Quitina Quitosano

Fig.1 Esquema de obtención de Quitosano por desacetilación química de la Quitina.

Dentro de las aplicaciones de la Quitina y el Quitosano se encuentran las siguientes (Agulló et al., 2004): se utilizan como agentes espesantes en alimentos para consumo humano, como estabilizante, espumante, ligante, emulsificante, quelante, humectante, como ayudante en la fabricación y texturización de proteínas solubles, como coadyuvante en la extensión de la vida de anaquel de encurtidos y como material de empaque biodegradable. Así también, se ocupa en la remoción de materia orgánica y metales pesados de aguas residuales y aguas naturales. Por otro lado, la Glucosamina es utilizada en el tratamiento del agua como clarificante y en el tratamiento de las osteoartritis, las proteínas o hidrolizados proteicos son muy importantes en la nutrición acuícola y la astaxantina es un pigmento usado en el alimento de cultivos de salmones, truchas y tilapias, a fin de que éstos adquieran un color rojizo.

Uno de los métodos más utilizados a nivel mundial para la extracción de Quitina de los desechos de crustáceos es el tratamiento químico con bases y ácidos fuertes. Este procedimiento involucra la desproteinización del material con hidróxido de sodio o de potasio, la desmineralización o eliminación de las sales minerales con ácido clorhídrico o ácido sulfúrico y la despigmentación o blanqueo por medio de agentes oxidantes tales como el permanganato de potasio o hipoclorito de sodio.

En la actualidad, en el Laboratorio de Ingeniería de Procesos de la Facultad de Ingeniería Química (FIQ), la Quitina se ha obtenido a partir de caparazón de camarón, a nivel de laboratorio, con un rendimientos en peso (base seca) del 24.5\%, con el propósito de producir Quitosano. Este biopolímero se ha utilizado extensivamente en trabajos de investigación como material adsorbente en la remoción de materia orgánica y metales pesados de aguas naturales y aguas residuales industriales.

Con la elaboración de este proyecto se pretendió sentar las bases para el montaje de una planta piloto con la capacidad de procesar $50 \mathrm{~kg}$ de caparazón de crustáceos por lote, para extraer Quitina con un rendimiento del $24.5 \%$ en base seca y proteínas. El resultado de este trabajo estableció la posibilidad de diseñar y construir una planta de producción de Quitina a nivel industrial por parte de la empresa Acuarius Internacional, ya que ésta produce un promedio de 12 contenedores de desechos de langostinos, equivalentes a 450,000 lbs mensuales (Arana, 2008).

\section{METODOLOGÍA}

\section{Material}

a) Caparazón de Crustáceos

Se trabajó con caparazón de camarón suministrado por la Empresa CAMANICA y con langostino, suministrado por Acuarius Internacional. Este material se seleccionó en tres grupos: (1) cabeza, (2) cola y (3) una mezcla de cabeza y cola $(50 / 50)$. 


\section{b) Reactivos}

Estos incluyen hidróxido de sodio al $50 \%(\mathrm{NaOH})$, ácido clorhídrico $12 \mathrm{~N}(\mathrm{HCl})$ e hipoclorito de sodio al $12 \%$ $(\mathrm{NaClO})$. Estos reactivos fueron adquiridos en grado comercial.

\section{Método}

a) Contenido de Humedad $(\% \mathrm{H})$

$10 \mathrm{~g}$ de materia prima, contenidos en una cápsula de porcelana, se introdujeron en un horno a $100{ }^{\circ} \mathrm{C}$ por 3 horas. Posteriormente, la muestra se dejó enfriar y se pesó. El \%H se calculó con base en la siguiente ecuación:

$$
\% \mathrm{H}=\frac{\text { masa seca }(\mathrm{g})}{\text { masa húmeda }(\mathrm{g})} \times 100
$$

\section{b) Proceso de Extracción de Quitina}

La extracción de Quitina a partir de los desechos de crustáceos involucró los siguientes procedimientos: lavado, pesado y trituración del material, desproteinización con $\mathrm{NaOH}$ al $10 \%$, desmineralización con $\mathrm{HCl} 1.8 \mathrm{~N}$, blanqueo con $\mathrm{NaClO}$ al $0.38 \%$, filtración, secado a $60^{\circ} \mathrm{C}$ y pesado. Para determinar el porcentaje de recuperación $(\% \mathrm{R})$ en cada una de las etapas, se utilizó la siguiente ecuación:

$$
\% \mathrm{R}=\frac{\text { Masa de Producto }(\mathrm{g})}{\text { Materia Prima inicial }(\mathrm{g})} \times 100
$$

c) Estudio para optimizar la cantidad de reactivos

Para llevar a cabo este estudio, se realizaron experimentos a escalas de laboratorio. El volumen y concentración de los reactivos utilizados se varió en cada una de las principales etapas (desproteinización, desmineralización y blanqueo). La descripción de las condiciones experimentales y las variables consideradas para cada tipo de material se muestra en la Tabla 1.

d) Recuperación de proteínas

Para la recuperación de proteínas se trabajó con las soluciones provenientes de la etapa de desproteinización. Para ello, la solución fue tratada con $\mathrm{HCl}$ conc. hasta alcanzar la precipitación, en el punto isoeléctrico, a un $\mathrm{pH}$ entre $3.5-4.5$. Posteriormente la mezcla fue filtrada, secada y almacenada.

\begin{tabular}{|c|c|c|c|c|c|}
\hline \multicolumn{6}{|l|}{ Caparazón de camarón } \\
\hline \multirow{2}{*}{ Reactivos } & \multicolumn{5}{|c|}{$\begin{array}{c}\text { No. Variables Experimentales } \\
\text { Volumen de reactivo por kg de Materia Prima (L) }\end{array}$} \\
\hline & \multicolumn{2}{|c|}{ I } & II & \multicolumn{2}{|c|}{ III } \\
\hline $\mathrm{NaOH} 10 \%$ & \multicolumn{2}{|l|}{5} & 4 & \multicolumn{2}{|c|}{3} \\
\hline $\mathrm{HCl} 1.8 \mathrm{~N}$ & \multicolumn{2}{|c|}{4} & 3 & \multicolumn{2}{|c|}{2} \\
\hline $\mathrm{NaClO} 0.38 \%$ & \multicolumn{2}{|l|}{4} & 3 & \multicolumn{2}{|c|}{8} \\
\hline \multicolumn{6}{|l|}{ Cabeza de Langostino } \\
\hline \multirow{2}{*}{ Reactivos } & \multicolumn{5}{|c|}{ No. Variables Experimentales } \\
\hline & I & & III & IV & $\mathrm{V}$ \\
\hline $\mathrm{NaOH} 10 \%$ & 5 & & 3 & \multicolumn{2}{|l|}{4} \\
\hline $\mathrm{HCl} 1.8 \mathrm{~N}$ & 4 & \multirow{2}{*}{ 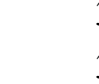 } & 2 & \multicolumn{2}{|r|}{$4^{*}$} \\
\hline $\mathrm{NaClO} 0.38 \%$ & 4 & & 8 & \multicolumn{2}{|l|}{12} \\
\hline \multirow{3}{*}{ Reactivos } & \multicolumn{3}{|c|}{ Cola } & \multicolumn{2}{|c|}{ Cabeza + Cola } \\
\hline & \multicolumn{3}{|c|}{ No. Variables Experimentales } & \multicolumn{2}{|c|}{ Variable Exp. } \\
\hline & I & II & III & & \\
\hline $\mathrm{NaOH} 10 \%$ & 3 & 4 & 4 & & \\
\hline $\mathrm{HCl} 1.8 \mathrm{~N}$ & 2 & 3 & $4 *$ & & \\
\hline $\mathrm{NaClO} 0.38 \%$ & 8 & 12 & $12 *$ & & \\
\hline
\end{tabular}

Tabla 1 Condiciones experimentales para cada tipo de crustáceo 
e) Propuesta técnica de diseño

Para elaborar la propuesta, fue imprescindible dimensionar el tamaño de los equipos. Para ello, se tomó como base el procesamiento de $50 \mathrm{~kg}$ de desechos de crustáceos, tal y como vienen de la planta procesadora. Dentro del análisis se consideró lo siguiente:

- Optimización de la cantidad de los reactivos y \% recuperación en cada una de las etapas.

- Balance de masa del proceso.

- Dimensionamiento de los equipos para procesar $50 \mathrm{~kg}$ de material en sistema Batch.

- Propuesta técnica de diseño de la planta piloto.

- Macro y micro localización de la planta piloto.

- Análisis económico para el montaje y operación de la planta piloto.

\section{RESULTADOS Y DISCUSION}

\section{Contenido de Humedad (\%H)}

El promedio de los resultados del $\% \mathrm{H}$ para cada tipo de material se presenta en la Tabla 2. En el caso del langostino, las pruebas se realizaron sin trituración $(\mathrm{S} / \mathrm{T})$ y con trituración $(\mathrm{C} / \mathrm{T})$ del material.

Tabla $2 \% \mathrm{H}$ de desechos de crustáceos

\begin{tabular}{lc}
\hline Descripción & $\% \mathrm{H}$ \\
\hline Caparazón de camarón & 76.7 \\
Cola de langostino (S/T) & 79.8 \\
Cola de langostino (C/T) & 76.2 \\
Cabeza de langostino (S/T) & 70.4 \\
Cabeza de langostino (C/T) & 68.0 \\
Cola+cabeza/langostino (S/T) & 75.1 \\
Cola+cabeza/langostino (C/T) & 72.1 \\
\hline
\end{tabular}

Los resultados muestran que el material viene de la planta procesadora con un alto contenido de humedad $(68-80 \%)$, correspondiendo entre $20-32 \%$ a materia seca, aproximadamente.

\section{Extracción de Quitina a partir de Caparazón de camarón}

En la figura 2 se presenta gráficamente el promedio de los resultados de la extracción de Quitina, con trituración y sin trituración del material.
Al llevar a cabo la extracción de Quitina con trituración de la materia prima, se observó que bajo las condiciones experimentales de la variable I se obtuvo una baja recuperación; además, que la Quitina producida no presentaba el color blanco característico sino que adquiría una coloración blanco hueso. Mientras que con las condiciones de la variable II, aunque se obtuvo un producto de mejor calidad, el \%Quitina producida fue más bajo. Por otro lado, aunque con las condiciones experimentales de la variable III se obtuvo un porcentaje de Quitina mayor (25.4\%), se observó que el producto presentaba mucha pigmentación. Este resultado indica que la cantidad de $\mathrm{NaOH} 10 \%$ utilizado no fue suficiente para que hubiera una buena desproteinización.

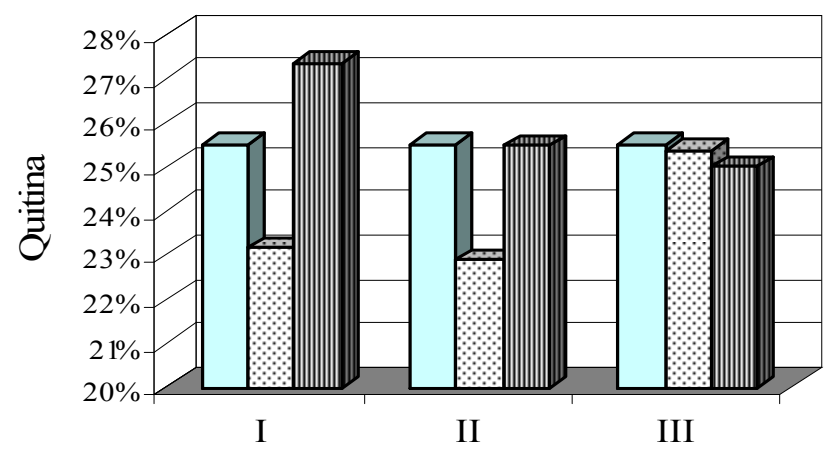

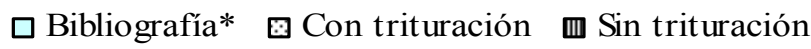

* Muzarelli (1977)

Fig. 2 Comparación del \% Quitina producida a nivel de laboratorio, con trituración y sin trituración del caparazón de camarón, con referencia bibliográfica.

Cuando la extracción de la Quitina se realizó sin trituración del material se observó que bajo las condiciones de la variable I, el producto tenía un color blanco hueso y tenía pigmentación en algunos puntos. El $\%$ Quitina obtenido fue mayor que el dado en la literatura, lo que puede indicar que el producto obtenido podía tener contaminación por exceso del hidróxido.

Durante los experimentos bajo las condiciones de las variables II y III, se consideró incrementar el período de agitación en la etapa de desproteinización a 2 horas, para garantizar la separación de las proteínas del sólido; así también, se aumentó el volumen de $\mathrm{NaClO}$ de 3 a 8 $\mathrm{lb} / \mathrm{kg}$ para eliminar la pigmentación del producto final. Bajo estas condiciones, se observaron mejores resultados ya que la Quitina producida tenía un color blanco homogéneo (sin pigmentos). 
De acuerdo a los resultados, se considera que las condiciones óptimas para producir Quitina a partir de caparazón de camarón sin trituración previa del material, serían: 3 lts de $\mathrm{NaOH}$ al 10\%/kg, 2 lts de $\mathrm{HCl} 1.8 \mathrm{~N} / \mathrm{kg}$ y 8 lts de $\mathrm{NaClO}$ al $0.38 \% / \mathrm{kg}$; con un tiempo de agitación de 2 horas en el período de desproteinización. Bajo estas condiciones, se puede obtener un \% Recuperación mayor que el 98\%.

\section{Extracción de Quitina a partir de cabeza de langostino}

La figura 3 muestra gráficamente los resultados de la extracción de Quitina, con trituración y sin trituración del material. Se puede observar que en casi todos los casos (excepto para la variable II) el mayor \%Quitina se obtiene cuando se trabaja con el material sin triturar.

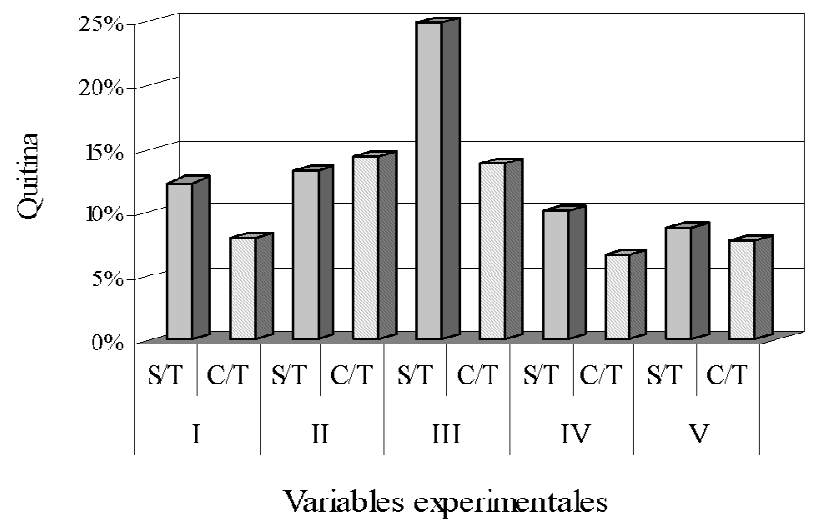

Fig. $3 \%$ Quitina producida a partir de cabeza de langostino, sin trituración y con trituración del material.

Con las condiciones experimentales de la variable I no se observó buena apariencia del material después de la desproteinización ya que se notaron pequeños residuos cárnicos. Después del período de desmineralización, la textura del producto era un poco dura lo que indicaba que éste todavía contenía sales de calcio. Durante el blanqueo no se observó una buena despigmentación del material (ver figura 4a).

Bajo las condiciones experimentales de la variable II y III se incrementó el tiempo de agitación en la etapa de desproteinización a 1.5 y 2 horas, respectivamente; observándose que el producto presentaba una buena apariencia y no contenía restos de residuos cárnicos. Sin embargo, después del período desmineralización, la textura del material todavía se mantenía dura y durante el blanqueo no se observó buena despigmentación del material.

Tomando en cuenta los resultados anteriormente obtenidos, para los siguientes experimentos se consideró incrementar la relación de volumen de cada reactivo en cada etapa (ver tabla 1 ).

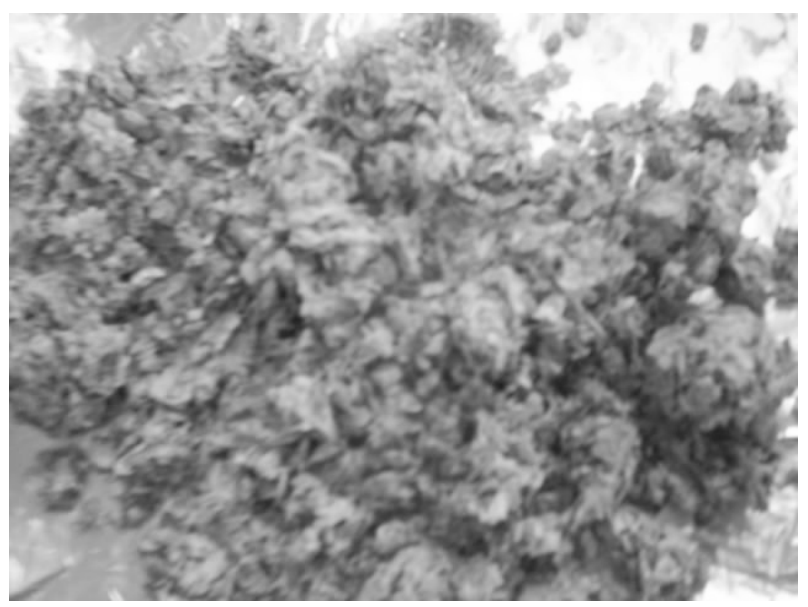

(a)

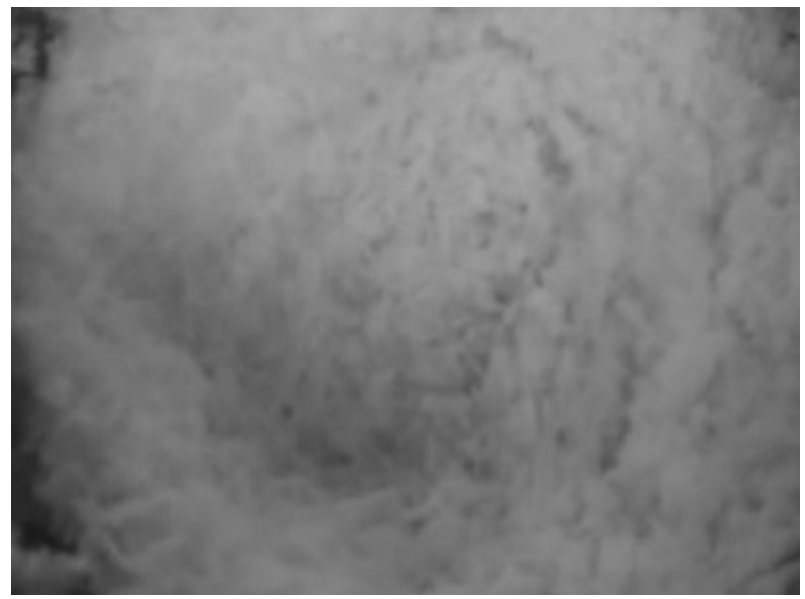

(b)

Fig. 4 Quitina extraída de cabeza de langostino con trituración del material, (a) con las condiciones de la variable I y (b) con las condiciones de la variable $\mathrm{V}$.

Con las condiciones experimentales de la variable IV y un tiempo de agitación de 2 horas en la etapa de desproteinización, se observó que la textura del material mostraba cierto grado de dureza y no había buena despigmentación del producto final. Considerando estos resultados, se varió la concentración de $\mathrm{HCl}$, así como el volumen y la concentración del $\mathrm{NaClO}$ para las próximas pruebas. Con las condiciones experimentales de la variable $\mathrm{V}$ y un período de agitación de 2 horas en la desproteinización, se observó que el material mostró una mejor apariencia: la textura era suave, blanca y sin pigmentos (ver figura $4 b$ ). 
Extracción de Quitina a partir de cola y cola/cabeza de Langostino

La figura 5 refleja los resultados obtenidos sin trituración y con trituración de la materia prima, observándose que en todos los casos el mayor \%Quitina se alcanza cuando el material no es triturado durante el proceso.

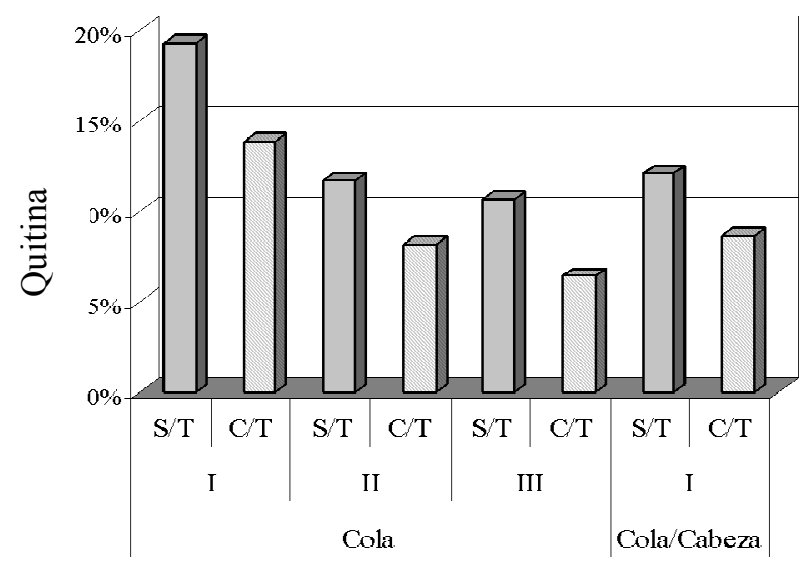

Fig. $5 \%$ Quitina producida a partir de cola y cola/cabeza de langostino, sin trituración y con trituración del material.

Cuando se trabajó con cola de langostino se observó que bajo las condiciones experimentales de la variable I y II, no hubo una buena apariencia del material ya que su textura no era suave y todavía mostraba residuos de pigmentos. Por otro lado, con las condiciones experimentales de la variable III: se observó una mejor apariencia del material después de la etapa de desproteinización. Posteriormente a la etapa de desmineralización, el producto presentaba una textura suave y después del blanqueo, la despigmentación del material ocurrió en su totalidad.

Habiendo realizado la optimización de reactivos para cola y cabeza de langostino, se utilizaron estas mismas condiciones de trabajo para llevar a cabo los experimentos con una mezcla de cabeza y cola de langostino (50/50). Como se puede observar en la figura 5 , se obtuvo un \%Quitina del $12 \%$ y el material producido presentaba una textura suave, blanca y sin pigmentos.

Considerando los resultados, se puede indicar que las condiciones óptimas para producir Quitina a partir de langostino son: $4 \mathrm{~L}$ de $\mathrm{NaOH}$ al $10 \%$, $4 \mathrm{~L}$ de $\mathrm{HCl} 3.6 \mathrm{~N}$ y
$12 \mathrm{~L}$ de $\mathrm{NaClO}$ al $0.76 \%$ por $\mathrm{kg}$ de material que entra a cada etapa.

\section{Recuperación de proteínas}

La recuperación de proteínas se llevó a cabo con las soluciones provenientes de la etapa de desproteinización del caparazón de camarón. Los resultados se muestran en la Tabla 3. Estos datos revelan que hay mayor precipitación de las proteínas a $\mathrm{pH}$ de 4.0 (mayor volumen de $\mathrm{HCl}$ conc.) y que se obtiene mayor cantidad de producto a partir de soluciones provenientes de la desproteinización de crustáceos sin triturar.

Tabla 3. Resultados de la recuperación de proteínas

\begin{tabular}{|c|c|c|c|c|}
\hline \multirow{3}{*}{$\begin{array}{c}\text { Descripción } \\
\mathrm{pH}\end{array}$} & \multicolumn{4}{|c|}{$\begin{array}{l}100 \mathrm{~mL} \text { Residuo de } \\
\text { Desproteinización }\end{array}$} \\
\hline & \multicolumn{2}{|c|}{$\mathrm{C} / \mathrm{T}$} & \multicolumn{2}{|c|}{$\mathrm{S} / \mathrm{T}$} \\
\hline & 4.0 & 4.5 & 4. & 4.5 \\
\hline $\begin{array}{l}\text { Vol. mL } \\
\text { (HCL conc) }\end{array}$ & 30.3 & 29.8 & 32. & 31.8 \\
\hline Proteína (g) & 2.3 & 2.1 & 2. & 2.0 \\
\hline
\end{tabular}

Propuesta técnica de la planta piloto

Para la propuesta técnica se tomó como base el procesamiento diario de $50 \mathrm{~kg}$ de desechos de crustáceos, las condiciones óptimas de las variables experimentales para el procesamiento de desechos de crustáceos (Tabla 4) y el \%Recuperación en cada una de las etapas del proceso (Tabla 5).

Tabla 4. Condiciones Experimentales para el proceso de desecho de crustáceos sin trituración de la materia prima

\begin{tabular}{lcl}
\hline \multicolumn{1}{c}{ Etapa } & $\begin{array}{c}\text { Caparazón } \\
\text { camarón }\end{array}$ & Langostino \\
\hline $\begin{array}{l}\text { Desproteinización } \\
\text { (Agitación } \times 2 \mathrm{~h})\end{array}$ & $\begin{array}{c}3 \mathrm{~L} / \mathrm{kg} \mathrm{de} \\
\mathrm{NaOH} 10 \%\end{array}$ & $\begin{array}{l}4 \mathrm{~L} / \mathrm{kg} \text { de } \\
\mathrm{NaOH} 10 \%\end{array}$ \\
& & \\
& & \\
Desmineralización & $\mathrm{L} / \mathrm{kg} \mathrm{de}$ & $4 \mathrm{~L} / \mathrm{kg} \mathrm{de} \mathrm{HC}$ \\
$($ Contacto $\times 12 \mathrm{~h})$ & $\mathrm{HCl} \mathrm{1.8 \textrm {N }}$ & $3.6 \mathrm{~N}$ \\
& & \\
& $8 \mathrm{~L} / \mathrm{kg} \mathrm{de}$ & $12 \mathrm{~L} / \mathrm{kg} \mathrm{de}$ \\
Blanqueo & $\mathrm{NaClO}$ & $\mathrm{NaClO}$ \\
$($ Agitación $\times 1 / 2 \mathrm{~h})$ & $0.38 \%$ & $0.76 \%$ \\
\hline
\end{tabular}




\section{Benavente et al}

\section{Balance de Masa}

El propósito de realizar los balances de masa para cada tipo de material (desechos de crustáceos) fue para determinar:

- el consumo de reactivo en cada una de las etapas para cada tipo de material,

- $\quad$ el mayor volumen de reactivo que se debe preparar en cada tanque,

- el tamaño de los tanques que almacenarán los reactivos $\mathrm{y}$,

- el tamaño del equipo (tanque reactor) donde se llevará a cabo el procesamiento de la materia prima.

En la tabla 5 se presenta el porcentaje de recuperación en cada etapa, el cual fue utilizado para realizar el balance de masa; así también, muestra el gasto de reactivo (en litros) en cada etapa, de acuerdo a los resultados obtenidos. La figura 6 muestra el balance de masa para el procesamiento de extracción de Quitina, a partir de cada tipo de material

Los resultados muestran que el mayor consumo de hidróxido de sodio es de $200 \mathrm{~L}$ en la etapa de desproteinización, de 92L de ácido clorhídrico en la etapa de desmineralización y de $107 \mathrm{~L}$ de hipoclorito de sodio en la etapa de blanqueo.

\section{Escalamiento de los equipos}

A continuación se detallan los equipos mayores y menores que forman parte del proceso productivo y del sistema de tratamiento de efluentes.

Tabla 5. \% Recuperación de producto y volumen de reactivo gastado en cada una de las etapas durante el procesamiento de Quitina a partir de desechos de crustáceos

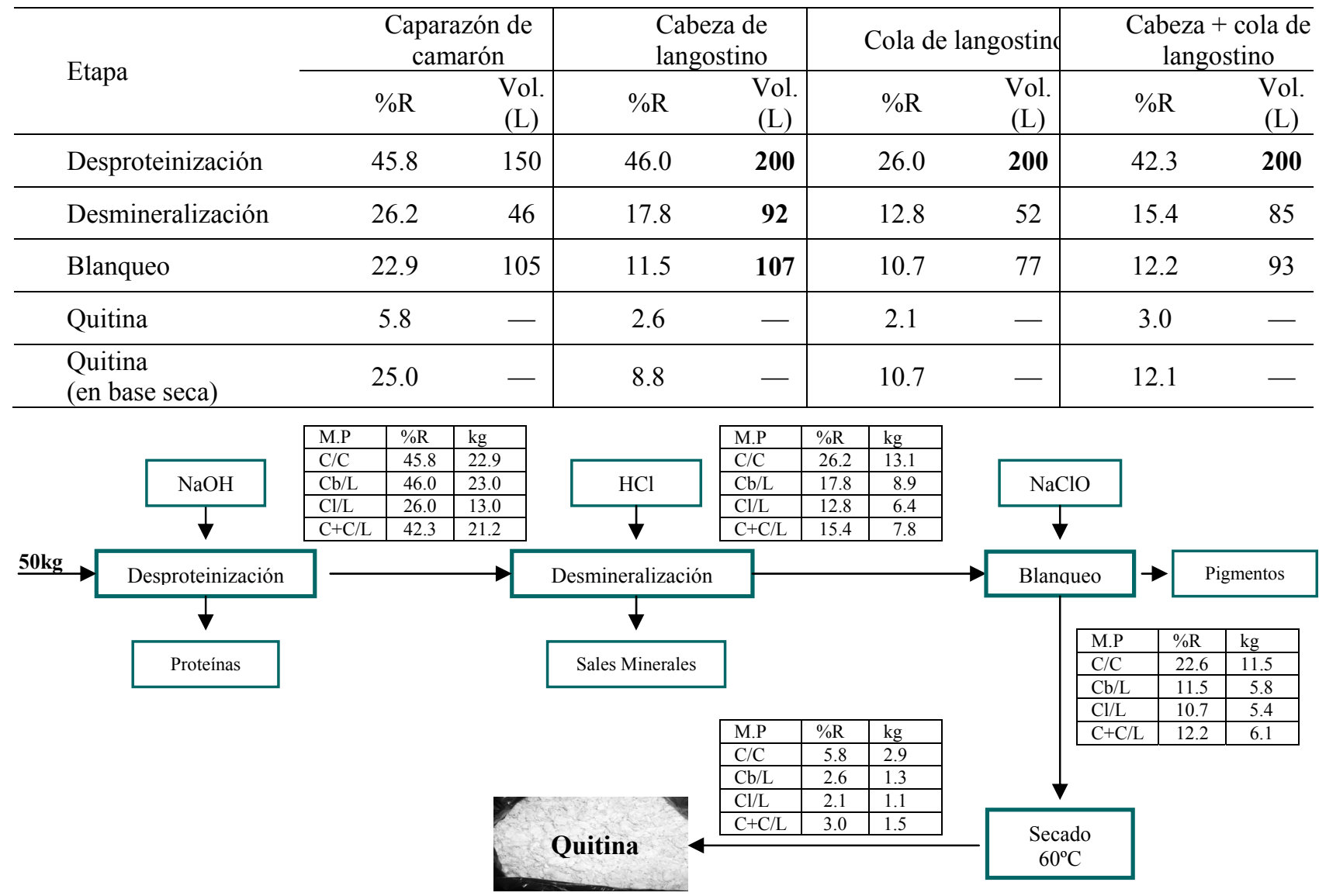

Fig. 6 Balance de masa para la producción de Quitina a partir de desechos de caparazón de camarón (C/C), cabeza de langostino $(\mathrm{Cb} / \mathrm{L})$, cola de langostino $(\mathrm{Cl} / \mathrm{L})$, cabeza + cola de langostino $(\mathrm{C}+\mathrm{C} / \mathrm{L})$, sin trituración previa de la materia prima. 


\section{a) Tanque Reactor}

A nivel de planta piloto, se consideró que la extracción de Quitina se llevaría a cabo en un sistema por lote en un tanque reactor, transformándolo en sucesivas operaciones hasta obtener el producto final. Según cálculos realizados, el tanque debe tener un volumen mínimo de 334 lts, considerando el suficiente espacio para permitir la agitación de la mezcla sin que haya rebalse. De acuerdo al proceso y los reactivos que se utilizan se puede considerar un tanque reactor de acero inoxidable o de plástico. Por los costos se planteó utilizar un tanque de 450 lts y acondicionarlo de tal forma que sirva a los propósitos mencionados.

Para evitar el problema de la separación sólido/líquido, se diseñó una canasta de acero inoxidable que contenga el material y se sumerja en la solución dentro del tanque reactor. El volumen de la canasta debe ser mayor que el volumen que ocupa $50 \mathrm{~kg}$ de material (aproximadamente 100L). Además, el tanque reactor debe contemplar la incorporación de un agitador de paleta para llevar a cabo la mezcla del sistema durante la etapa de desproteinización y la etapa de blanqueo. Debe estar montado en una estructura de acero para darle resistencia y estabilidad, principalmente durante el proceso de agitación.

La figura 7a muestra el tanque reactor equipado con una canasta de acero inoxidable y un agitador de paleta. Los volúmenes totales del tanque de reactor y de la canasta son de $428 \mathrm{~L}$ y $167.3 \mathrm{~L}$, respectivamente, los cuales son mayores que los volúmenes anteriormente señalados.

\section{b) Tanque de recuperación de proteínas}

Con el propósito de extraer las proteínas de la solución que proviene del proceso de desproteinización, se usó un tanque de plástico de $450 \mathrm{~L}$, provisto de un agitador de paletas (ver figura $7 b$ ). El tanque esta montado en una estructura de acero para darle resistencia y estabilidad.

c) Tanques de almacenamiento de reactivos

Para el almacenamiento y preparación de los reactivos ( $\mathrm{NaOH}, \mathrm{HCl}$ y $\mathrm{NaClO}$ ) se necesitaron tres tanques. De acuerdo al balance de masa (ver tabla 5), la mayor cantidad de reactivo a preparar, para una masa inicial de $50 \mathrm{~kg}$ material es de $200 \mathrm{~L}$. Por lo que se planteó la adquisición de tanques de plástico de 250L con dimensiones de $70 \times 82 \mathrm{~cm}$.

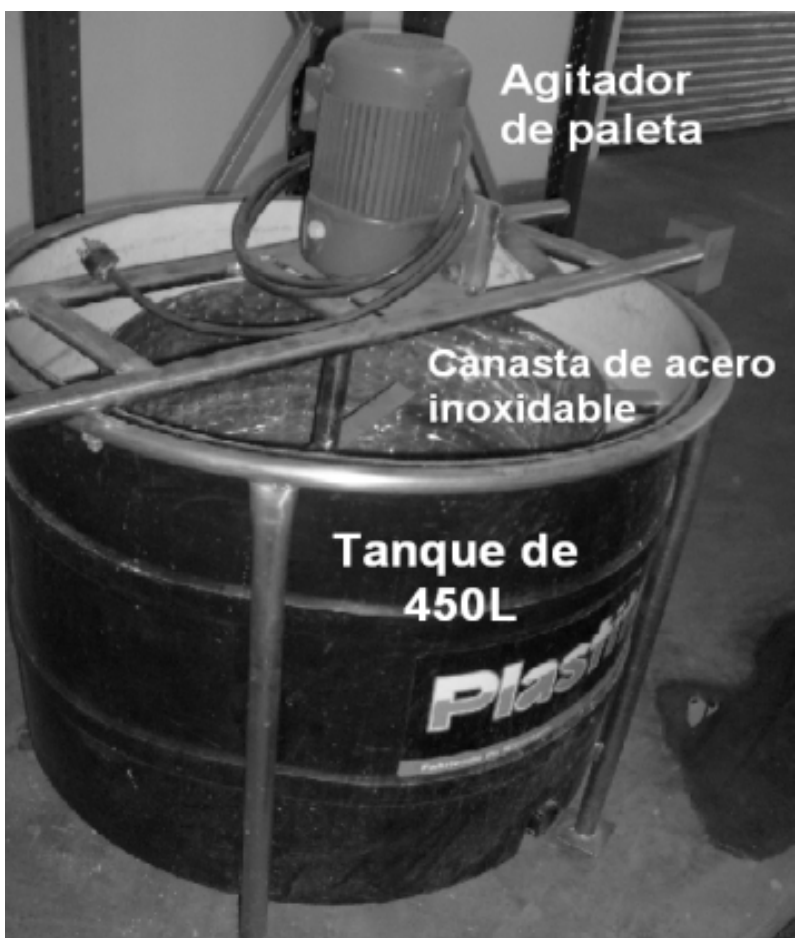

(a)

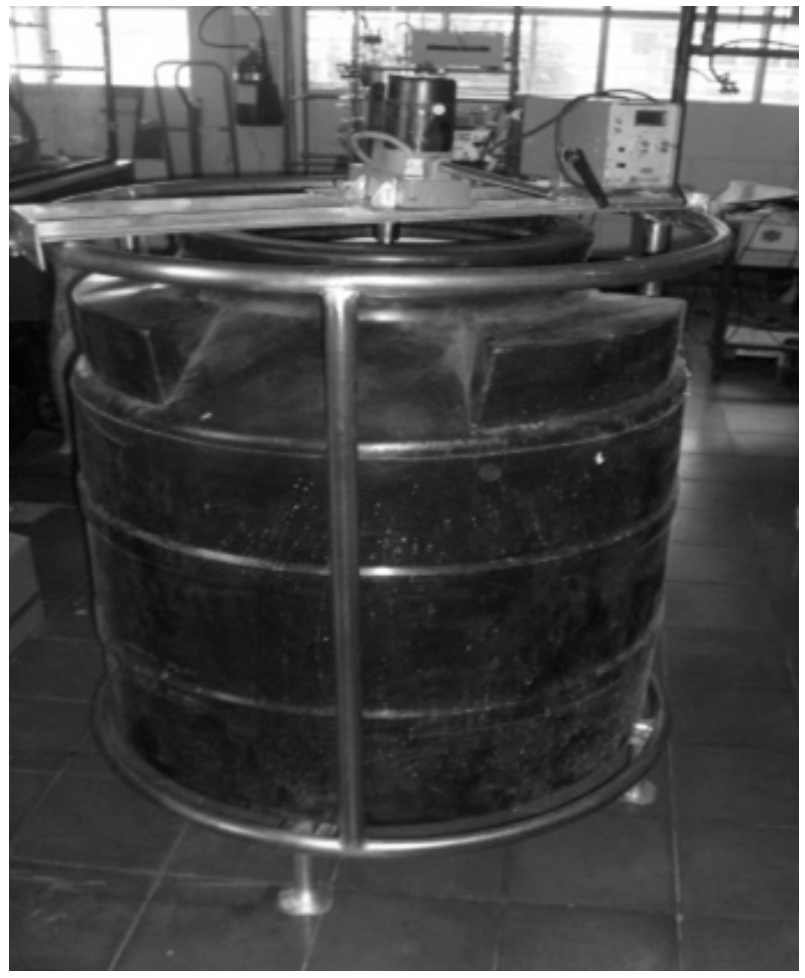

(b)

Fig. 7 (a) Tanque reactor de 450L para el procesamiento de desechos de crustáceos y (b) Tanque para precipitación de proteínas. 


\section{Benavente et al}

\section{d) Tanque de Almacenamiento de Agua}

Por problemas de flujo y escasez de agua potable, se planteó la necesidad de incorporar un tanque de $750 \mathrm{~L}$ para el almacenamiento del agua, provisto de una bomba eléctrica para el transporte del líquido a los tanques de preparación de reactivos y el lavado del material.

e) Tanque de tratamiento de desechos líquidos

Éste servirá para el almacenamiento de efluentes líquidos que provienen de las etapas de desmineralización y blanqueo, con el propósito de tratar por neutralización estos efluentes antes de ser desechados al drenaje.

f) Otros materiales y suministros

Otros equipos menores necesarios para el procesamiento en la planta piloto fueron: balanza de $0-100 \mathrm{~kg}$, freezer de $186 \mathrm{~L}$ y un horno de $350^{\circ} \mathrm{C}$.

Además, se consideró la estructura de la planta (ver figura 8), el sistema eléctrico, que incluye cable eléctrico, paneles y breakers; y otros materiales para el sistema de tuberías, tales como bombas de $0.5 \mathrm{hp}$, tubos PVC, tubos T, codos, válvulas, bridas, etc.

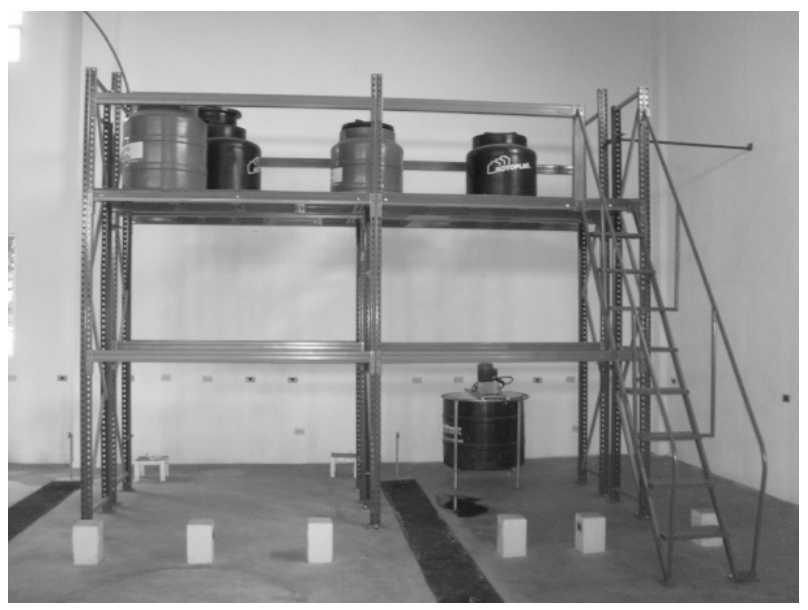

Fig.8 Estructura de la planta piloto

\section{Macro y Micro localización de la Planta Piloto}

Geográficamente, la planta piloto se ubicó en el Laboratorio de Operaciones Unitarias de la Facultad de Ingeniería Química, UNI. Este edificio está ubicado en el costado noroeste de la UNI, contiguo al Instituto de Estudios Superiores (IES), en Managua.

Para seleccionar un lugar específico en el edificio se consideraron las características del lugar y el acceso a servicios generales. Por ello, se planteó la microlocalización de la planta en el costado noroeste del edificio con un área de $44.2 \mathrm{~m}^{2}$. En la estructura de la planta (ver figura 8) se puede observar que en la parte superior se ubican los tanques de almacenamiento de reactivos, para que éstos drenen por gravedad al tanque reactor, el cual está ubicado en la planta baja.

\section{Análisis económico}

El estudio técnico del proyecto proporcionó información básica sobre los costos e inversión del proceso operativo $\mathrm{y}$ costos de todos los componentes, datos sobre las instalaciones y los equipos que están asociados al proceso productivo.

\section{a) Costos de las Instalaciones y Equipos}

En la tabla 6. se muestra un resumen de los costos de los materiales y accesorios, sistema eléctrico, equipos mayores y menores, montaje de estructura y mano de obra para el montaje de la planta piloto.

Tabla 6. Costos para el Montaje de la Planta Piloto

\begin{tabular}{|c|c|c|}
\hline Descripción & $\begin{array}{c}\text { P/Total } \\
\text { (C\$) }\end{array}$ & $\begin{array}{c}\text { P/Total } \\
\text { (US\$) } \\
\end{array}$ \\
\hline Materiales y Accesorios & $14,999.10$ & 728.11 \\
\hline Sistema eléctrico & $8,471.01$ & 411.21 \\
\hline Tanques & $81,133.80$ & $3,938.53$ \\
\hline Estructura de la planta & $97,627.45$ & $4,739.20$ \\
\hline Mano de obra & $14,500.00$ & 703.89 \\
\hline Total & $216,731.31$ & $10,520.9$ \\
\hline
\end{tabular}

De acuerdo a la tabla anterior, se necesita invertir C\$ 216,731.36 (US\$ 10,520.94) para el montaje de la planta a nivel piloto.

b) Costos de reactivos y transporte

Para operar la planta, se calculó el monto requerido para el procesamiento de la Quitina por 6 meses (27 semanas). Esto involucra: transporte del material desde la planta procesadora y gastos de reactivos concentrados $(\mathrm{NaOH} 50 \%, \mathrm{HCl} 12 \mathrm{~N}$ y $\mathrm{NaClO} 12 \%)$. Se calculó un monto de C $\$ 99,963.18$ (US\$ 4,852.58) en reactivos y de C\$7,200.00 (US\$ 350.00) en gastos de transporte. 
c) Para producir $1 \mathrm{~kg}$ de Quitina

Considerando los datos obtenidos con los balances de masa y el costo de los reactivos en el mercado local, se calculó el costo total para producir $1 \mathrm{~kg}$ de Quitina a partir de caparazón de camarón y cabeza de langostino. Los resultados mostraron que para producir $1 \mathrm{~kg}$ de Quitina a partir de caparazón de camarón el costo es de US\$ 30.98 y a partir de cabeza de langostino es de US\$ 135.94 .

\section{Análisis Ambiental}

Para la propuesta de un sistema de tratamiento:

- Se identificaron las principales corrientes de desechos durante el procesamiento de quitina.

- Se analizó el marco regulatorio de los residuos líquidos del proceso y las restricciones para el descargue de los residuos líquidos, considerando las variables económicas, sociales y ambientales.

- Se hizo una propuesta para el sistema de tratamiento de los residuos y/o su aprovechamiento en otras etapas del proceso.

Durante el proceso, las principales corrientes de desecho son aguas residuales provenientes de productos secundarios de la reacción, reactivos agotados o contaminados que no pueden ser reutilizados y aguas de lavado de las fracciones sólidas. Se identificó que Los efluentes líquidos pueden dividirse en tres grupos:

- Residuos líquidos de la etapa de desproteinización: está compuesto principalmente por una importante carga orgánica constituida por proteínas; así como, restos de hidróxido de sodio. El $\mathrm{pH}$ de estos residuos líquidos es de aproximadamente 13.85.

- Residuos líquidos de la etapa de Desmineralización: está compuesto por minerales de calcio y magnesio disueltos, y restos de ácido clorhídrico. $\mathrm{El} \mathrm{pH}$ de estos efluentes es de aproximadamente de 1.04.

- Residuos líquidos de la etapa de Blanqueo: compuesto por restos de pigmentos y $\mathrm{NaClO}$, el cual puede servir como agente desinfectante. $\mathrm{El} \mathrm{pH}$ de estos efluentes varía entre 7.5 y de 9.3.

Un subproducto valioso que se puede recuperar de los residuos líquidos del proceso de desproteinización son las proteínas, las cuales son macromoléculas formadas por cadenas lineales de aminoácidos, y pueden ser utilizadas como suplemento en comida animal de pollos y pescado. Según Agulló et al. (2004) los residuos pueden ser tratados con $\mathrm{HCl} 12 \mathrm{~N}$ hasta alcanzar la precipitación, en el punto isoeléctrico, a un $\mathrm{pH}$ entre 3.5 -4.5 .

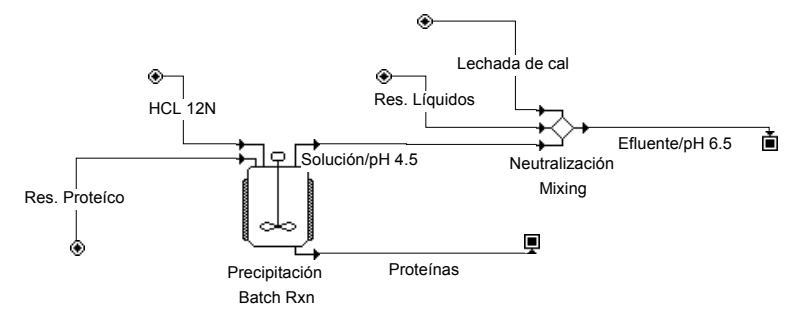

Fig.9 Diagrama de flujos del proceso de precipitación de proteínas y neutralización de efluentes líquidos (Programa SuperPro Designer)

El uso de una lechada de cal al 5\%p/v permite lograr una efectividad de neutralización, es menos costosa que la sosa cáustica y no forma precipitados con el ácido clorhídrico.

\section{CONCLUSIONES}

El estudio mostró que las condiciones óptimas para la obtención de Quitina a partir de desechos de crustáceos dependen fuertemente de las características del material. Para procesar caparazón de camarón, sin trituración previa a la etapa del proceso, se encontró que estas condiciones fueron: $3 \mathrm{~L}$ de $\mathrm{NaOH}$ al $10 \% / \mathrm{kg}$ (desproteinización), $2 \mathrm{~L} \quad \mathrm{de} \quad \mathrm{HCl} \quad 1.8 \mathrm{~N} / \mathrm{kg}$ (desmineralización) y $8 \mathrm{~L}$ de $\mathrm{NaClO}$ al $0.38 \% / \mathrm{kg}$ (blanqueo). Mientras que para el langostino, las condiciones fueron: $4 \mathrm{~L}$ de $\mathrm{NaOH}$ al $10 \%$, $4 \mathrm{~L}$ de $\mathrm{HCl}$ $3.6 \mathrm{~N}$ y $12 \mathrm{~L}$ de $\mathrm{NaClO}$ al $0.76 \%$ por $\mathrm{kg}$ de material.

Para garantizar una buena remoción de las proteínas y eliminación de los residuos cárnicos del material, se debe tener un tiempo de agitación de 2 horas durante la etapa de desproteinización y de 1 hora, en la etapa de blanqueo para el langostino, y de media hora para caparazón de camarón.

El estudio para la recuperación de proteínas mostró que la mayor producción de proteínas ocurre a $\mathrm{pH} 4.0$ y con soluciones provenientes del proceso sin trituración previa de la materia prima.

El escalamiento de los equipos y el análisis técnicoeconómico de la planta piloto se realizó con base en los volúmenes gastados, encontrándose que se debe tener una inversión inicial de C\$216,731.36 (US\$ 10,520.94) para el montaje de la planta piloto y de C\$ 
99,963.18 (US\$ 4,852.58) para gastos de transporte y operación para seis meses.

Debido a que todos los reactivos utilizados durante el proceso son bases y ácidos fuertes, se debe incluir un sistema de tratamiento para neutralizar los efluentes antes de ser descargados al ambiente.

\section{AGRADECIMIENTOS}

Los autores agradecen a la Vice-Rectoría de Investigación y Desarrollo y al Programa UNI-Asdi-FIQ por el apoyo financiero para la realización de este estudio. Así también, a las Empresas CAMANICA y Acuarius International por el suministro de la materia prima.

\section{ABREVIATURA}

$\begin{array}{ll}\% \mathrm{H} & \text { Contenido de humedad } \\ \% \mathrm{R} & \text { Porcentaje de Recuperación } \\ \mathrm{S} / \mathrm{T} & \text { Sin trituración } \\ \mathrm{C} / \mathrm{T} & \text { Con trituración } \\ \mathrm{C} / \mathrm{C} & \text { Caparazón de camarón } \\ \mathrm{Cb} / \mathrm{L} & \text { Cabeza de langostino } \\ \mathrm{Cl} / \mathrm{L} & \text { Cola de langostino } \\ \mathrm{C}+\mathrm{C} / \mathrm{L} & \text { Cola }+ \text { cabeza de langostino }\end{array}$

\section{REFERENCIAS}

Agulló, E., et al. (2004). Quitina y Quitosano: Obtención, Caracterización y Aplicaciones. pp. 244245. Fondo Editorial 2004. Pontificia Universidad Católica del Perú.

Arana, J. (2008) Comunicación Personal. Empresa Acuarius International INC. Managua, Nicaragua.

Gerente, C., et al. (2007). Application of Chitosan for the Removal of Metals from Wastewaters by Adsorption - Mechanisms and Models Review. Vol. 37 pp. 41127.Critical Reviews in Environmental Science \& Technology.

Malafaya, P.B., et al. (2007). Natural-Origin Polymers as Carriers and Scaffolds for Biomolecules a Cell Delivery in Tissue Engineering Applications. Advanced Drug Delivery Reviews, Vol. 59. pp. 207-233.

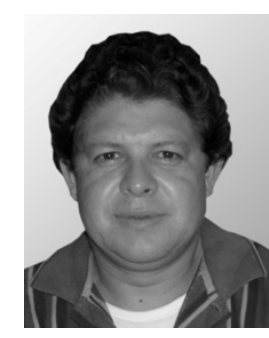

Denis Escorcia Morales se graduó de la carrera de Ingeniería Química en el año 2009. Obtuvo su título, con el tema de investigación: "Propuesta para el montaje de una planta piloto para la obtención de Quitina". Responsable de Laboratorio de Química, Facultad de Ingeniería Química, Universidad Nacional de Ingeniería.

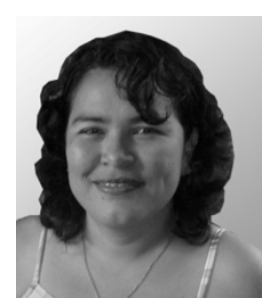

Daysi del Carmen Hernández Díaz se graduó de la carrera de Ingeniería Química en el año 2009. Obtuvo su título, con el tema de investigación: "Propuesta para el montaje de una planta piloto para la obtención de Quitina”.

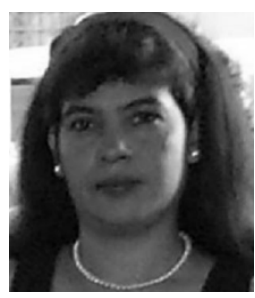

Maritza Sánchez Christoffle se graduó en Ingeniería Química, en 1996, en la Universidad Nacional de Ingeniería. Obtuvo el grado de Maestría en Procesamiento de Alimentos con mención en Producción más Limpia, en el 2003, y una especialidad en Medio Ambiente, en el CIDIAT, Mérida, Venezuela. Profesor Titular de la Facultad de Ingeniería Química, Universidad Nacional de Ingeniería.

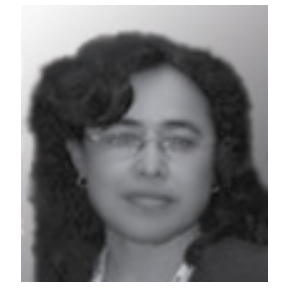

Martha Benavente Silva se graduó de Licenciada en Química en la UNAN-León, en 1987. Obtuvo el grado de M.Sc. en Ingeniería Química en la Universidad de Chile, en 2005 y el grado de LicEng en Ingeniería Química en el Real Instituto Tecnológico (KTH) de Suecia, en 2008. Actualmente está realizando sus estudios de Ph.D en Ingeniería Química en esta última institución. Sus intereses de investigación incluyen: procesamiento de biopolímeros a partir de crustáceos, remoción de metales pesados de aguas naturales y residuales. Profesor Titular, Facultad de Ingeniería Química, Universidad Nacional de Ingeniería. 